\title{
H-ras Oncogene Mutation in Dedifferentiated Chondrosarcoma: Polymerase Chain Reaction- Restriction Fragment Length Polymorphism Analysis
}

Akio Sakamoto, M.D., Yoshinao Oda, M.D., Toshisada Adachi, M.D., Yumi Oshiro, M.D., Sadafumi Tamiya, M.D., Kazuhiro Tanaka, M.D., Shuichi Matsuda, M.D., Yukihide Iwamoto, M.D., Masazumi Tsuneyoshi, M.D.

Department of Anatomic Pathology, Pathological Sciences (AS, YoO, TA, ST, MT), and Department of Orthopaedic Surgery (KT, SM, YI), Graduate School of Medical Sciences, Kyushu University, Fukuoka, and Department of Pathology, Matsuyama Red Cross Hospital (YuO), Matsuyama, Japan

Dedifferentiated chondrosarcomas, which are known for their poor prognosis, are characterized by conventional chondrosarcoma with high-grade anaplastic components. Activating mutations in ras genes are a common genetic abnormality in human malignancies. The presence of point mutations at codons 12 and 13 of the $\mathrm{H}$-ras gene was studied in 20 formalin-fixed paraffin-embedded chondrosarcomas, comprising 11 cases of conventional chondrosarcoma (six Grade 1 cases and five Grade 2 cases) and nine cases of dedifferentiated chondrosarcoma, using polymerase chain reactionrestriction fragment length polymorphism and direct sequencing analysis. H-ras mutations were only seen in two out of the nine cases of dedifferentiated chondrosarcoma $(2 / 9,22 \%)$ and they were not seen in any of the cases of conventional chondrosarcoma $(0 / 11,0 \%)$. Dedifferentiated chondrosarcomas had a worse prognosis than conventional chondrosarcomas $(P<.01)$; among the patients with dedifferentiated chondrosarcomas, those with $\mathrm{H}$-ras mutation $(n=2)$ tended to have a worse prognosis than those without $(n=7)$, although the difference was not statistically significant $(P=0.068)$. Our results would seem to suggest that $\mathrm{H}$-ras mutation may occur during the course of dedifferentiation and may also have some effect on malignant potential.

KEY WORDS: Dedifferentiated chondrosarcoma, Conventional chondrosarcoma, H-ras mutation,

Copyright () 2001 by The United States and Canadian Academy of Pathology, Inc.

VOL. 14, NO. 4, P. 343, 2001 Printed in the U.S.A.

Date of acceptance: October 10, 2000.

Address reprint requests to: Masazumi Tsuneyoshi, M.D., Department of Anatomic Pathology, Pathological Sciences, Graduate School of Medical Sciences, Kyushu University, 3-1-1 Maidashi, Higashi-ku, Fukuoka, 8128582, Japan; e-mail: masazumi@surgpath.med.kyushu-u.ac.jp; fax: 81-92-642-5968.
PCR-RFLP.

Mod Pathol 2001;14(4):343-349

Dedifferentiated chondrosarcoma is a unique phenotype of chondrosarcoma, which was first described by Dahlin and Beabout in 1971 (1). Histologically, it is characterized by the coexistence of low- to intermediate-grade chondrosarcoma and high-grade pleomorphic sarcoma that shows the features of malignant fibrous histiocytoma (MFH), osteosarcoma and fibrosarcoma. This type of chondrosarcoma comprises approximately $10 \%$ of all chondrosarcomas (2) and shows an increased growth rate and rapid metastatic spread in comparison with ordinary chondrosarcomas (3). In other bone tumors, the phenomenon of dedifferentiation has been reported in low-grade osteosarcoma $(4,5)$, chordoma (6) and giant cell tumor (7).

Single-point mutations of the ras genes (K-ras, $\mathrm{H}$-ras, and $\mathrm{N}$-ras) usually at codons 12,13 and 61 result in a single amino acid substitution in critical domains and this substitution has a significant role to play in tumor development by rendering the proteins no longer dependent on GTPase-activating protein regulation (8). Frequent ras mutations have been reported in a number of human cancers, including adenocarcinoma of the pancreas $(90 \%)$, colon (50\%), thyroid (50\%), and lung (30\%) (9). The $\mathrm{H}$-ras gene is commonly activated in human urinary tract tumors (10). As for sarcomas, H-ras mutations have been reported in MFH, leiomyosarcoma, and rhabdomyosarcoma (11-14); however, $\mathrm{H}$-ras mutations have not been reported in chondrosarcomas. Moreover, H-ras mutations were not detected in two previous series of chondrosarcoma $(15,16)$, and the contribution of $\mathrm{H}$-ras mutation to dedifferentiation has not been fully examined.

In the present study, we searched for $\mathrm{H}$-ras mutations at codons 12 and 13 in a series of chondro- 
sarcomas (conventional chondrosarcoma and dedifferentiated chondrosarcoma) to clarify whether or not $\mathrm{H}$-ras mutations were present in these tumors.

\section{MATERIALS AND METHODS}

\section{Specimens}

Formalin-fixed paraffin-embedded tissue blocks from a total of 20 cases of chondrosarcoma comprising 11 cases of conventional chondrosarcoma and nine cases of dedifferentiated chondrosarcoma were used in this study, with the specimens being decalcified when needed. All the cases were collected from the histopathology files at our institute. The histologic grading was performed according to Evans et al. (17). The 11 cases of conventional chondrosarcoma comprised six Grade 1 and five Grade 2 cases. In the nine cases of dedifferentiated chondrosarcoma, there were four Grade 1 and five Grade 2 cartilaginous components. The high-grade anaplastic components of dedifferentiated chondrosarcoma demonstrated the features of MFH (eight cases) and osteosarcoma (one case).

\section{Formalin-Fixed Paraffin-Embedded Tissue DNA Extraction}

DNA was extracted from a $50-\mu \mathrm{m}$ paraffinembedded tissue section as follows. Paraffin was removed with xylene and then the sample was washed twice with $100 \%$ ethanol and subsequently dried. The tissue was suspended in digestion buffer (100 mm sodium chloride, $10 \mathrm{~mm}$ Tris-hydrochloric acid, $25 \mathrm{~mm}$ ethylenediaminetetraacetic acid and $0.5 \%$ sodium dodecyl sulfate) containing $10 \mu \mathrm{g}$ proteinase $\mathrm{K}$, before being incubated overnight at $55^{\circ} \mathrm{C}$. DNA, precipitated by adding twice the volume of ethanol, was washed with $70 \%$ ethanol, before being resuspended in TE buffer (10 mM Tris, $1 \mathrm{~nm}$ ethylenediaminetetraacetic acid) for storage at $4^{\circ} \mathrm{C}$.

\section{Polymerase Chain Reaction-Restriction Fragment Length Polymorphism (PCR-RFLP)}

We used the PCR-RFLP procedure to detect H-ras mutations at codons 12 and 13 with strategy primers as reported (18). Table 1 summarizes the prim-

TABLE 1. PCR Primers Used to Amplify DNA for RFLP and Direct Sequencing

\begin{tabular}{ll}
\hline $1^{\text {st }}$ PCR & \\
Sense & $5^{\prime}$-GGAGACCCTGTAGGAGGACCC-3' \\
Anti-sense & $5^{\prime}$-TCTATAGTGGGGTCGTATTCGTCC-3' \\
Nested PCR and direct & \\
sequencing & $5^{\prime}$-TGAGGAGCGATGACGGAAT-3' \\
Sense & $5^{\prime}$-ATGGTCAGCGCACTCTTGCCCTC-3' \\
Anti-sense & \\
\hline \multicolumn{2}{l}{ PCR, polymerase chain reaction; RFLP, restriction fragment length } \\
polymorphism analysis.
\end{tabular}

ers used in our study. DNA sequences containing codons 12 and 13 of the $\mathrm{H}$-ras gene were amplified using the primers 5'-GGAGACCCTGTAGGAGGACCC-3' and 5'-TCTATAGTGGGGTCGTATTCGTCC-3' for 35 cycles $\left(95^{\circ} \mathrm{C}\right.$ for $1 \mathrm{~min}, 59^{\circ} \mathrm{C}$ for $1 \mathrm{~min}$, and $72^{\circ} \mathrm{C}$ for $\left.2 \mathrm{~min}\right)$. Then, $5 \mu \mathrm{l}$ of the amplified products that had been diluted 100 -fold were reamplified by means of nested PCR using the mutant primers 5'-TGAGGAGCGATGACGGAAT-3' and 5'ATGGTCAGCGCACTCTTGCCCTC-3' for 30 cycles $\left(92^{\circ} \mathrm{C}\right.$ for 15 seconds, $55^{\circ} \mathrm{C}$ for 15 seconds, and $72^{\circ} \mathrm{C}$ for 30 seconds). Codon 12 mutations could be detected due to a naturally occurring HpaII site (CCGG) that is lost when the mutation occurs. HpaII digests the 71-bp amplified fragment into two fragments (41-bp and 30-bp), thereby revealing the presence of the normal allele, while the mutant allele remains within the undigested 71-bp fragment. This method enables the detection of a mutation at the second and third positions of codon 11 and at the first and second positions of codon 12 . With regard to codon 13 mutations, nested primers were used to create a new restriction site for Hph I (GGTGA) by changing a $\mathrm{T}$ for an $\mathrm{A}$ in the second position of codon 14, thus enabling the detection of any mutation of codon 13 of the $\mathrm{H}$-ras gene. Hph I digests the same 71-bp amplified fragment into two fragments (58-bp and 13-bp), thereby revealing the presence of the normal allele, while the mutant allele remains within the undigested $71-\mathrm{bp}$ fragment. The DNA bands were analyzed by $3 \%$ agarose gel electrophoresis, stained with ethidium bromide and then photographed.

\section{Direct Sequencing}

After samples of the digested products were obtained from agarose gels and amplified by the same primers used for the nested PCR, the amplified product was purified by Microcon centrifugal filter devices (Millipore, Bedford, Massachusetts). After purification, direct sequencing was carried out by the dideoxy chain termination method using a Perkin Elmer ABI Prism 310 sequence analyzer (Applied Biosystems, Foster City, California). The primers used for direct sequences were the same sense and anti-sense primers used for the nested PCR.

\section{Statistical Analysis}

The results of $\mathrm{H}$-ras mutations were compared with clinicopathologic features using the $\chi^{2}$ test or Fisher exact test for qualitative data and using the Mann-Whitney $U$ test for quantitative data. The survival estimates were determined by KaplanMeier analysis, and the survival differences were evaluated by the Log-rank test. A $P$ value of less 
than 0.05 was considered to indicate statistical significance.

\section{RESULTS}

\section{Clinical Findings}

Table 2 summarizes the clinicopathologic data. The conventional chondrosarcomas (six Grade 1 and five Grade 2 cases) used in this study had developed late in life, at a median age of 54.4 years (range 24 to 78 years). Six cases were male and five were female (M/F: 1.2/1). The bones affected by conventional chondrosarcoma comprised the humerus (four cases), femur (three cases), pelvis (two cases), fibula (one case), and frontal bone (one case) in descending order of frequency. Similarly, the dedifferentiated chondrosarcomas were also seen late in life, at a median age of 51.5 years (range 37 to 85 years). Three cases were male and six were female (M/F: 1/2.0). The bones affected by dedifferentiated chondrosarcoma comprised the femur (five cases), rib (two cases), pelvis (one case), and tibia (one case) in descending order of frequency. The affected ages were not statistically different between the patients with conventional chondrosarcoma and those with dedifferentiated chondrosarcoma.

All of the tumors had been excised as an initial treatment. In the case of the tumors developing in long bones, wide resections had been carried out. Dedifferentiated chondrosarcoma had a significantly worse survival rate than conventional chondrosarcoma $(P<.01)$ (Fig. 1).

\section{Histologic Features}

Chondrosarcoma has an overall lobulated architecture and the individual lobules were separated

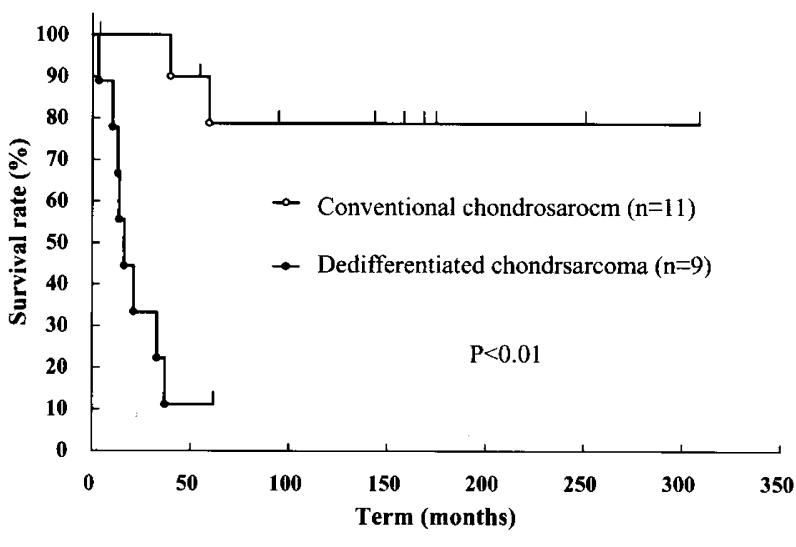

FIGURE 1. Kaplan-Meier survival curves for chondrosarcoma according to tumor subtype, conventional chondrosarcoma versus dedifferentiated chondrosarcoma. Dedifferentiated chondrosarcoma shows a significantly worse prognosis than conventional chondrosarcoma $(P<.01)$.

by narrow fibrovascular bands (Fig. 2). Grade 1 chondrosarcoma was cytologically very similar to chondroma; however, tumor cells with mild nuclear atypia and binucleation were occasionally noted (Fig. 3). Grade 2 chondrosarcoma showed high cellularity, loss of lobular architecture and numerous binucleated cells, and was also associated with myxoid matrix (Fig. 4).

Dedifferentiated chondrosarcoma was characterized by the coexistence of conventional chondrosarcoma and high-grade anaplastic components (Fig. 5). The high-grade anaplastic components consisted of atypical spindled and pleomorphic cells arranged in short fascicles or sometimes storiform patterns, resembling the pathologic features of MFH (Fig. 6). In one case in particular (CS70), the high-grade anaplastic components showed irregular osteoid formation embedded in cellular prolif-

TABLE 2. Clinicopathological Data and H-ras Mutation in Chondrosarcomas

\begin{tabular}{|c|c|c|c|c|c|c|c|}
\hline Case & Age/Sex & Site & Histology & Grade/HG-Area & Codon/H-ras Mutation & \multicolumn{2}{|c|}{ Follow-Up } \\
\hline CS12 & $55 / \mathrm{M}$ & Fibula & Conventional CS & Grade 1 & - & $175 \mathrm{mo}$ & Alive \\
\hline CS44 & $24 / F$ & Pelvis & Conventional CS & Grade 1 & - & $169 \mathrm{mo}$ & Alive \\
\hline CS47 & $59 / \mathrm{M}$ & Femur & Conventional CS & Grade 1 & - & $144 \mathrm{mo}$ & Alive \\
\hline CS57 & $47 / \mathrm{M}$ & Humerus & Conventional CS & Grade 1 & - & $251 \mathrm{mo}$ & Alive \\
\hline CS34 & $78 / \mathrm{F}$ & Humerus & Conventional CS & Grade 1 & - & $59 \mathrm{mo}$ & DOD \\
\hline CS111 & $24 / \mathrm{F}$ & Femur & Conventional CS & Grade 1 & - & $4 \mathrm{mo}$ & Alive \\
\hline CS5 & $46 / \mathrm{M}$ & Humerus & Conventional CS & Grade 2 & - & $95 \mathrm{mo}$ & Alive \\
\hline CS9 & $54 / \mathrm{M}$ & Pelvis & Conventional CS & Grade 2 & - & $158 \mathrm{mo}$ & Alive \\
\hline CS40 & $75 / \mathrm{M}$ & Humerus & Conventional CS & Grade 2 & - & $40 \mathrm{mo}$ & DOD \\
\hline CS62 & $42 / \mathrm{F}$ & Frontal bone & Conventional CS & Grade 2 & - & $309 \mathrm{mo}$ & Alive \\
\hline CS77 & $62 / \mathrm{F}$ & Femur & Conventional CS & Grade 2 & - & $54 \mathrm{mo}$ & Alive \\
\hline CS69 & $53 / \mathrm{F}$ & Femur & Dedifferentiated CS & Grade 2/MFH-like & 12/GGC-GCC(Gly-Ala) & $3 \mathrm{mo}$ & DOD \\
\hline CS93 & $59 / \mathrm{M}$ & Femur & Dedifferentiated CS & Grade 2/MFH-like & 12/GGC-AGC(Gly-Ser) & $14 \mathrm{mo}$ & DOD \\
\hline CS3 & $85 / F$ & Femur & Dedifferentiated CS & Grade 1/MFH-like & - & $21 \mathrm{mo}$ & DOD \\
\hline CS68 & $59 / \mathrm{F}$ & Femur & Dedifferentiated CS & Grade 1/MFH-like & - & $16 \mathrm{mo}$ & DOD \\
\hline CS70 & $37 / F$ & Tibia & Dedifferentiated CS & Grade 1/OS-like & - & $13 \mathrm{mo}$ & DOD \\
\hline CS85 & $63 / \mathrm{F}$ & Rib & Dedifferentiated CS & Grade 1/MFH-like & - & $10 \mathrm{mo}$ & DOD \\
\hline CS23 & $45 / \mathrm{F}$ & Rib & Dedifferentiated CS & Grade 2/MFH-like & - & $62 \mathrm{mo}$ & Alive \\
\hline CS54 & $38 / \mathrm{M}$ & Pelvis & Dedifferentiated CS & Grade 2/MFH-like & - & $37 \mathrm{mo}$ & DOD \\
\hline CS92 & $51 / \mathrm{M}$ & Femur & Dedifferentiated CS & Grade 2/MFH-like & - & $33 \mathrm{mo}$ & DOD \\
\hline
\end{tabular}

CS, chondrosarcoma; MFH, malignant fibrous histiocytoma; OS, osteosarcoma; HG, high-grade anaplastic; Gly, glycine; Ala, alanine; Ser, serine; A, adenine; G, guanine; C, cytosine; DOD, died of the disease. 


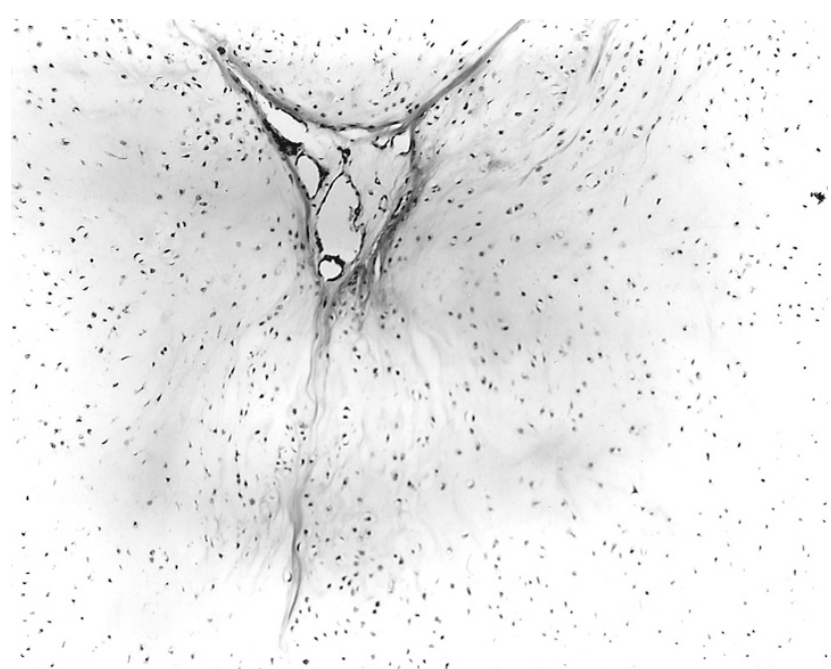

FIGURE 2. Grade 1 conventional chondrosarcoma is characterized by lobulated architecture with abundant cartilaginous matrix separated by narrow fibrovascular bands (hematoxylin and eosin, original magnification, $\times 60)$.

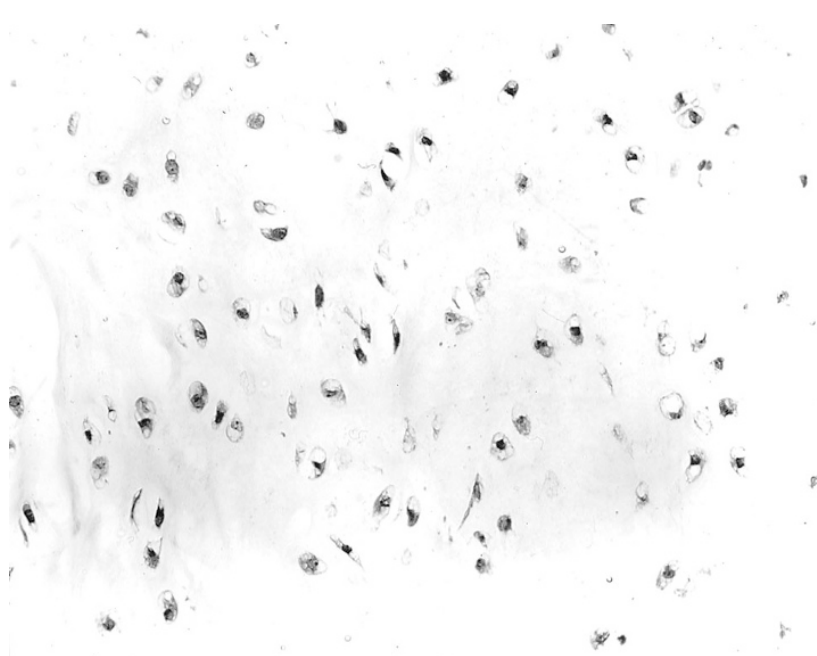

FIGURE 3. Grade 1 conventional chondrosarcoma; the tumor cells resembling those of chondroma lie in the lacunar space surrounding the hyaline cartilaginous matrix (hematoxylin and eosin, original magnification, $\times 200)$.

eration of atypical cells, suggesting osteosarcomalike features.

\section{$\mathrm{H}$-ras Mutations}

Table 2 lists the occurrence of $\mathrm{H}$-ras mutations in chondrosarcomas. Figure 7 shows the representative data. Dedifferentiated chondrosarcoma showed $\mathrm{H}$-ras mutations in two out of the nine cases $(22 \%)$. These occurred at codon 12 (GGC-toGCC [Gly-Ala] and GGC-to-AGC [Gly-Ser]). H-ras mutations were not seen in any of the cases of conventional chondrosarcoma (Grade 1 [0/6; 0\%] and Grade $2[0 / 5 ; 0 \%])$. Among the dedifferentiated chondrosarcoma cases, the patients with $\mathrm{H}$-ras mutations had a worse survival rate than those without

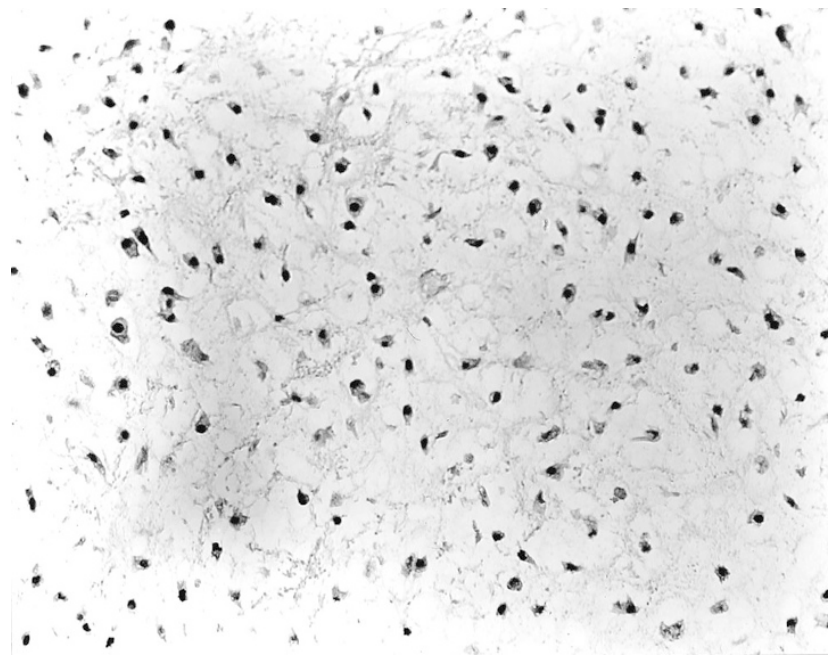

FIGURE 4. Grade 2 conventional chondrosarcoma; the tumor cells with cellular atypia have increased cellularity and myxoid matrix (hematoxylin and eosin, original magnification, $\times 200$ ).

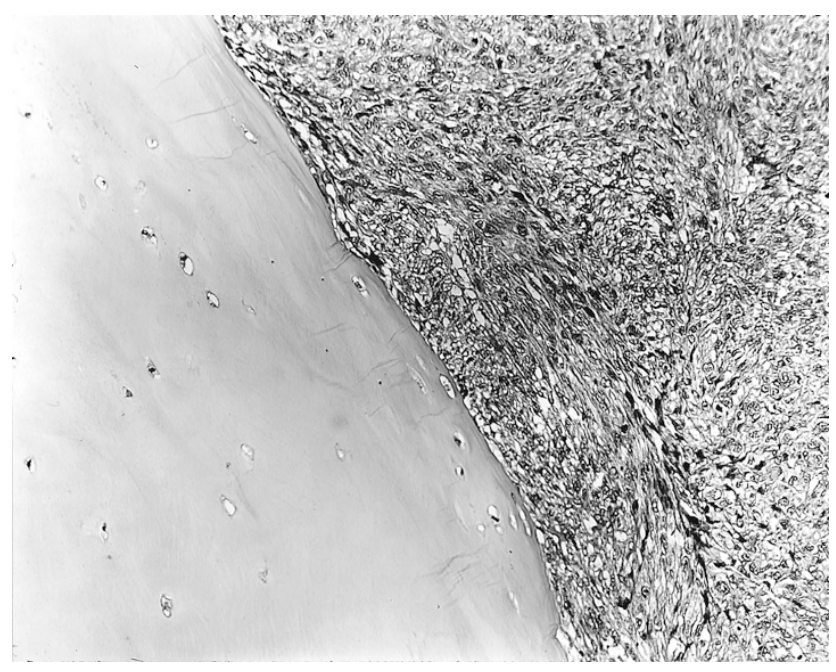

FIGURE 5. Dedifferentiated chondrosarcoma is characterized by the coexistence of low-grade chondrosarcoma (Grade 1) (left) and highgrade anaplastic components resembling malignant fibrous

histiocytoma (right) with a distinct border (hematoxylin and eosin, original magnification, $\times 150)$.

$\mathrm{H}$-ras mutations, although the difference was not statistically significant $(P=0.068)$ (Fig. 8).

\section{DISCUSSION}

Histologically, dedifferentiated chondrosarcoma shows the coexistence of cartilaginous components and high-grade anaplastic components, suggesting MFH-like features in most cases. In the current study, high-grade anaplastic components showed MFH-like features in eight cases, and the other one case showed osteosarcoma-like features. Dedifferentiated chondrosarcoma has a poor prognosis with high invasive or metastatic potential (3). In our cases, dedifferentiated chondrosarcoma had a significantly worse survival rate than conventional 


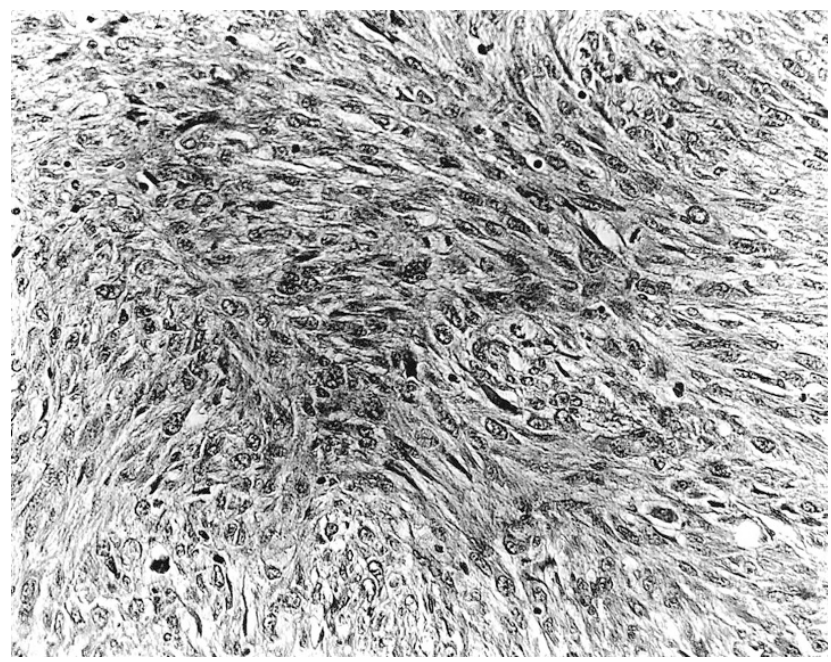

FIGURE 6. Dedifferentiated chondrosarcoma; high-grade anaplastic components are composed of atypical spindled cells with malignant fibrous histiocytoma-like features (hematoxylin and eosin, original magnification, $\times 200)$.

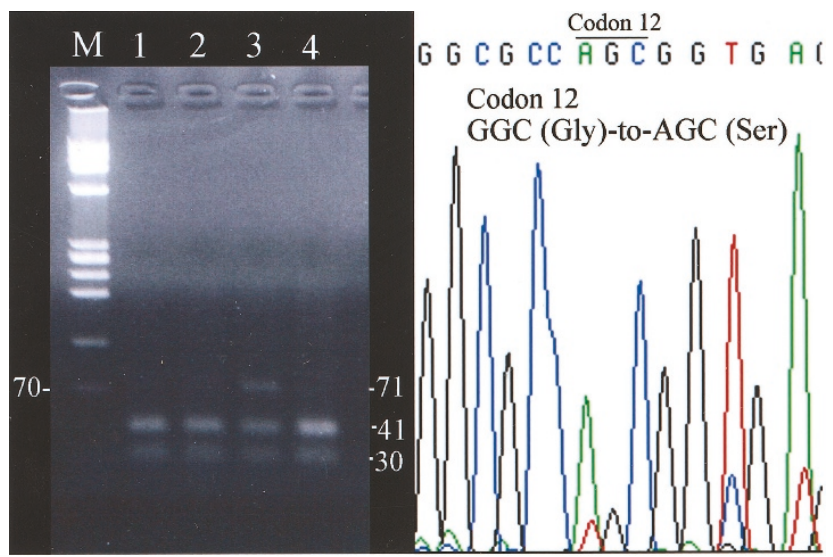

FIGURE 7. Dedifferentiated chondrosarcoma, (Case CS 93: femur, 59-year-old male). HpaII digested the amplified DNA fragments (71 bp) including codons 12 into 41-bp and 30-bp fragments in a normal case (lanes 1, 2, and 4), while a mutant case remained undigested (lane 3). $\phi$ $\mathrm{X} 174$ was used as the size marker (left). Consequently, direct sequencing was performed on the sample in lane 3 . The figure shows the $\mathrm{H}$-ras sense sequence and indicates that the first position of codon 12 of the sense strand was mutated from $\mathrm{G}$ to $\mathrm{A}$, this change resulting in the code for serine instead of glycine (right).

chondrosarcoma $(P<.01)$. Eight of the nine cases of dedifferentiated chondrosarcoma died of this disease (8/9: $89 \%$ ), and their survival terms were less than 5 years from the time of diagnosis.

In the present study, we used PCR-RFLP analysis and direct sequencing to detect the presence of $\mathrm{H}$-ras mutations at codons 12 and 13 in our series of chondrosarcoma. This method of PCR-RFLP analysis can detect $\mathrm{H}$-ras mutations without using any radioactive material, and even when the mutations are present in only $5 \%$ of the genes, these mutations are still detectable (18).

As for sarcomas, H-ras mutations have been reported in MFH, leiomyosarcoma and rhabdomyo-

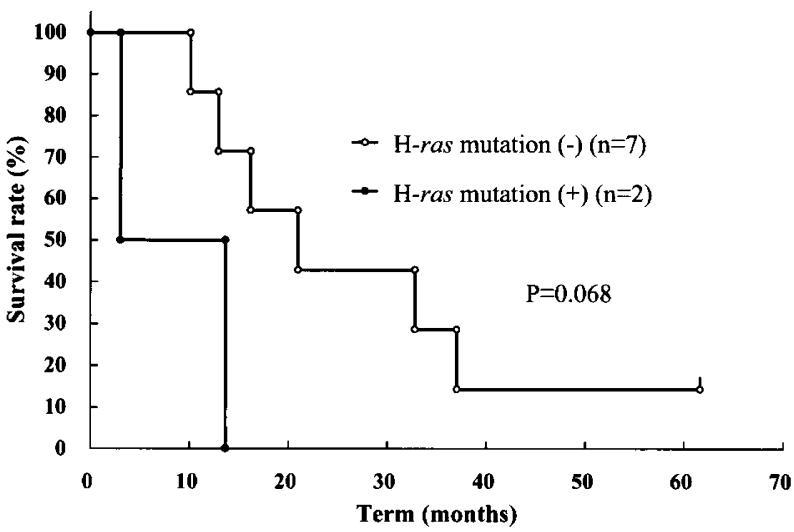

FIGURE 8. Kaplan-Meier survival curves for dedifferentiated chondrosarcoma according to an occurrence of H-ras mutation; H-ras mutation $(-)$ versus $\mathrm{H}$-ras mutation $(+)$. Dedifferentiated chondrosarcoma with $\mathrm{H}$-ras mutation tended to have a worse prognosis than that without $(P=0.068)$.

sarcoma (11-14). However, to our knowledge, H-ras mutations in chondrosarcoma have not been previously reported. On the contrary, it has been reported that none of six chondrosarcomas demonstrated ras gene mutations (K-ras, $\mathrm{H}$-ras, and $\mathrm{N}$-ras) at codons 12, 13, and 61 (15), and that neither of two chondrosarcomas showed $\mathrm{H}$-ras mutation at codon 12 (16). This document would therefore seem to be the first report to verify the presence of $\mathrm{H}$-ras mutation in a series of chondrosarcoma.

Sawyer et al. reported that chromosome aberrations in the region of 6q13-21 were associated with locally aggressive behavior in their cases of benign and malignant cartilaginous tumors including dedifferentiated chondrosarcoma, and that increasing complexity of karyotypes had been seen during tumor progression in chondrosarcoma (19). Indeed, the $6 \mathrm{q} 13$ breakpoint has been reported in two cases of high-grade chondrosarcoma, comprising one Grade 2 chondrosarcoma (20) and one dedifferentiated chondrosarcoma (21). Overexpression and/or alteration of p53 were demonstrated to be correlated with the histologic grade and the presence of metastasis (22). Actually, it has also been reported that p53 mutations were predominantly present in higher-grade chondrosarcomas or dedifferentiated chondrosarcoma (23-25).

In the current study, $\mathrm{H}$-ras mutations were seen in two out of nine cases of dedifferentiated chondrosarcoma (22\%). On the other hand, H-ras mutations were not observed in any of the cases of conventional chondrosarcoma (0/11; 0\%) (Grade 1 $[0 / 6]$ and Grade $2[0 / 5])$. The patients with dedifferentiated chondrosarcoma who demonstrated $\mathrm{H}$-ras mutation had a worse prognosis than those without $\mathrm{H}$-ras mutation, although the difference was not statistically significant, perhaps due to the small number of cases. It may also be that the deletion of the $\mathrm{H}$-ras allele coincidences with the 
loss of another gene located within the proximity of the H-ras gene, which is located on the short arm of chromosome 11 (26). In fact, Bovee et al. detected $\mathrm{LOH}$ (loss of heterozygosity) on chromosomes 11 and amplification on 11q in their one case of dedifferentiated chondrosarcoma (27). The presence of $\mathrm{H}$-ras mutation has been shown to contribute to increased genetic instability (28), which also is considered to contribute to tumor progression and metastasis (29-31). Therefore, the fact the H-ras mutations were found in dedifferentiated chondrosarcomas also lends support to the possibility that this type of chondrosarcoma is associated with genetic instability.

Previous studies demonstrated that the highgrade anaplastic components in dedifferentiated chondrosarcoma had a worse malignant potential compared with the other well-differentiated components, in that high-grade anaplastic components exhibited a strikingly increased proliferation rate as revealed by Ki-67 and proliferating cell nuclear antigen immunohistochemical staining (32), while also showing over-immunoexpression of $\mathrm{u}-\mathrm{PA}$ (urokinase-type plasminogen activator), t-PA (tissue plasminogen activator), PAI-1 (plasminogen activator inhibitor-1) (33), p53 (32), and MMP-2 (matrix metalloproteinase-2) and MT1-MMP (membrane type-1 matrix metalloproteinase) (34).

The mechanism of dedifferentiation is controversial as to whether the cartilaginous and high-grade anaplastic components are both derived from a common precursor cell (35), since Johnson et al. surmised that these clones of dedifferentiated sarcoma are unstable and may eventually fail to reach the same level of differentiation, resulting in aggressive additional components (36), or whether the high-grade anaplastic components are in fact derived from a separate genotypic lineage $(37,38)$. Bovee et al. showed the same p53 mutation and deletion of the same copies of chromosome 13 using CGH (comparative genomic hybridization) and $\mathrm{LOH}$ analysis in both cartilaginous and high-grade anaplastic components in dedifferentiated chondrosarcoma. Accordingly, they surmised that the shared components are monoclonal in origin and that these alterations occurred before the separation into two components in dedifferentiated chondrosarcoma (27).

The importance of H-ras mutations in dedifferentiation is unknown, because the incidence of $\mathrm{H}$-ras mutations in dedifferentiated chondrosarcoma is low, which would thereby suggest that it is not critical for dedifferentiation. For further consideration of $\mathrm{H}$-ras mutation in dedifferentiated chondrosarcoma, it would be appropriate to analyze the two components of dedifferentiated chondrosarcoma independently using a microdissection method.
In the present study, we examined the occurrence of $\mathrm{H}$-ras mutations in a series of chondrosarcoma. We were able to detect $\mathrm{H}$-ras mutations only in dedifferentiated chondrosarcoma, and not in conventional chondrosarcoma. Moreover, among the dedifferentiated chondrosarcoma cases, those cases with $\mathrm{H}$-ras mutation had a worse prognosis compared with the cases without H-ras mutation, although the difference was not statistically significant. Our results would seem to suggest that the presence of $\mathrm{H}$-ras mutations may be associated with malignant potential in dedifferentiated chondrosarcoma, while actually occurring during the dedifferentiation process itself.

Acknowledgments: Financial support provided by a Grant-in-Aid for Cancer Research from the Fukuoka Cancer Society, Fukuoka, and a Grant-in-Aid for General Scientific Research from the Ministry of Education, Science and Culture (09470052, 12670167), Tokyo, Japan. The English used in this manuscript was revised by Miss K. Miller (Royal English Language Center, Fukuoka, Japan).

\section{REFERENCES}

1. Dahlin DC, Beabout JW. Dedifferentiation of low-grade chondrosarcomas. Cancer 1971;28:461-6.

2. Dorfman HD, Czerniak B, editors. Bone tumors. St Louis: Mosby; 1998.

3. Campanacci M, Bertoni F, Capanna R. Dedifferentiated chondrosarcomas. Ital J Orthop Traumatol 1979;5:331-41.

4. Iemoto Y, Ushigome S, Fukunaga M, Nikaido T, Asanuma K. Central low-grade osteosarcoma with foci of dedifferentiation. Skeletal Radiol 1991;20:379-82.

5. Wold LE, Unni KK, Beabout JW, Sim FH, Dahlin DC. Dedifferentiated parosteal osteosarcoma. J Bone Joint Surg Am 1984;66:53-9.

6. Fleming GF, Heimann PS, Stephens JK, Simon MA, Ferguson MK, Benjamin RS, et al. Dedifferentiated chordoma. Response to aggressive chemotherapy in two cases. Cancer 1993;72:714-8.

7. Meis JM, Dorfman HD, Nathanson SD, Haggar AM, Wu KK. Primary malignant giant cell tumor of bone: "dedifferentiated” giant cell tumor. Mod Pathol 1989;2:541-6.

8. Barbacid M. ras genes. Annu Rev Biochem 1987;56:779-827.

9. Bos JL. ras oncogenes in human cancer: a review. Cancer Res 1989;49:4682-9.

10. Fujita J, Yoshida O, Yuasa Y, Rhim JS, Hatanaka M. Aaronson SA. Ha-ras oncogenes are activated by somatic alterations in human urinary tract tumours. Nature 1984;309:464-6.

11. Wilke W, Maillet M, Robinson R. H-ras-1 point mutations in soft tissue sarcomas. Mod Pathol 1993;6:129-32.

12. Bohle RM, Brettreich S, Repp R, Borkhardt A, Kosmehl H, Altmannsberger HM. Single somatic ras gene point mutation in soft tissue malignant fibrous histiocytomas. Am J Pathol 1996;148:731-8.

13. Yoo J, Robinson RA, Lee J-Y. H-ras and K-ras gene mutations in primary human soft tissue sarcoma: concomitant mutations of the ras gene, Mod Pathol 1999;12:775-80.

14. Yoo J, Robinson RA. H-ras and K-ras mutations in soft tissue sarcoma: comparative studies of sarcomas from Korean and American patients. Cancer 1999;86:58-63. 
15. Pompetti F, Rizzo P, Simon RM, Freidlin B, Mew DJ, Pass HI, et al. Oncogene alterations in primary, recurrent, and metastatic human bone tumors. J Cell Biochem 1996;63:37-50.

16. Barrios C, Castresana JS, Ruiz J, Kreicbergs A. Amplification of c-myc oncogene and absence of c-Ha-ras point mutation in human bone sarcoma. J Orthop Res 1993;11:556-63.

17. Evans HL, Ayala AG, Romsdahl MM. Prognostic factors in chondrosarcoma of bone: a clinicopathologic analysis with emphasis on histologic grading. Cancer 1977;40:818-31.

18. Capella G, Matias-Guiu X, Ampudia X, de Leiva A, Perucho $\mathrm{M}$, Prat J. Ras oncogene mutations in thyroid tumors: polymerase chain reaction-restriction-fragment-length polymorphism analysis from paraffin-embedded tissues. Diagn Mol Pathol 1996;5:45-52.

19. Sawyer JR, Swanson CM, Lukacs JL, Nicholas RW, North PE, Thomas JR. Evidence of an association between 6q13-21 chromosome aberrations and locally aggressive behavior in patients with cartilage tumors. Cancer 1998;82:474-83.

20. Dijkhuizen T, van den Berg E, Molenaar WM, Oosterhuis JW, Dam A, Wiersema J, et al. Cytogenetics as a tool in the histologic subclassification of chondrosarcomas. Cancer Genet Cytogenet 1994;76:100-5.

21. Swarts SJ, Neff JR, Johansson SL, Bridge JA. Cytogenetic analysis of dedifferentiated chondrosarcoma. Cancer Genet Cytogenet 1996;89:49-51.

22. Oshiro Y, Chaturvedi V, Hayden D, Nazeer T, Johnson M, Johnston DA, et al. Altered p53 is associated with aggressive behavior of chondrosarcoma: a long term follow-up study. Cancer 1998;83:2324-34.

23. Terek RM, Healey JH, Garin-Chesa P, Mak S, Huvos A, Albino AP. p53 mutations in chondrosarcoma. Diagn Mol Pathol 1998;7:51-6.

24. Dobashi Y, Sugimura H, Sato A, Hirabayashi T, Kanda H, Kitagawa $\mathrm{T}$, et al. Possible association of p53 overexpression and mutation with high-grade chondrosarcoma. Diagn Mol Pathol 1993;2:257-63.

25. Yamaguchi $T$, Toguchida J, Wadayama B, Kanoe H, Nakayama T, Ishizaki K, et al. Loss of heterozygosity and tumor suppressor gene mutations in chondrosarcomas. Anticancer Res 1996;16:2009-15.

26. Heim S, Mitelman F. Nineteen of 26 cellular oncogenes precisely localized in the human genome map to one of the 83 bands involved in primary cancer-specific rearrangements. Hum Genet 1987;75:70-2.

27. Bovee JV, Cleton-Jansen AM, Rosenberg C, Taminiau AH, Cornelisse CJ, Hogendoorn PC. Molecular genetic character- ization of both components of a dedifferentiated chondrosarcoma, with implications for its histogenesis. J Pathol 1999;189:454-62.

28. Denko NC, Giaccia AJ, Stringer JR, Stambrook PJ. The human Ha-ras oncogene induces genomic instability in murine fibroblasts within one cell cycle. Proc Natl Acad Sci USA 1994;91:5124-8.

29. Reddy MA, Langer SJ, Colman MS, Ostrowski MC. An enhancer element responsive to ras and fms signaling pathways is composed of two distinct nuclear factor binding sites. Mol Endocrinol 1992;6:1051-60.

30. Basu TN, Gutmann DH, Fletcher JA, Glover TW, Collins FS, Downward J. Aberrant regulation of ras proteins in malignant tumour cells from type 1 neurofibromatosis patients. Nature 1992;356:713-5.

31. Ren M, Drivas G, D'Eustachio P, Rush MG. Ran/TC4: a small nuclear GTP-binding protein that regulates DNA synthesis. J Cell Biol 1993;120:313-23.

32. Simms WW, Ordonez NG, Johnston D, Ayala AG, Czerniak B. p53 expression in dedifferentiated chondrosarcoma. Cancer 1995;76:223-7.

33. Hackel C, Czerniak B, Ayala AG, Radig K, Roessner A. Expression of plasminogen activators and plasminogen activator inhibitor 1 in dedifferentiated chondrosarcoma. Cancer 1997;79:53-8.

34. Sakamoto A, Oda Y, Iwamoto Y, Tsuneyoshi M. Expression of membrane type 1-matrix metalloproteinase, matrix metalloproteinase-2 and tissue inhibitor of metalloproteinase-2 in human cartilaginous tumors with special emphasis on mesenchymal and dedifferentiated chondrosarcoma. J Cancer Res Clin Oncol 1999;125:541-8.

35. Bridge JA, DeBoer J, Travis J, Johansson SL, Elmberger G, Noel SM, et al. Simultaneous interphase cytogenetic analysis and fluorescence immunophenotyping of dedifferentiated chondrosarcoma. Implications for histopathogenesis. Am J Pathol 1994;144:215-20.

36. Johnson S, Tetu B, Ayala AG, Chawla SP. Chondrosarcoma with additional mesenchymal component (dedifferentiated chondrosarcoma). I. A clinicopathologic study of 26 cases. Cancer 1986;58:278-86.

37. Rywlin AM. Chondrosarcoma of bone with "dedifferentiation" Hum Pathol 1982;13:963-4.

38. Tetu B, Ordonez NG, Ayala AG, Mackay B. Chondrosarcoma with additional mesenchymal component (dedifferentiated chondrosarcoma). II. An immunohistochemical and electron microscopic study. Cancer 1986;58:287-98. 